\title{
THE SIGNIFICANCE OF PROLONGED STREPTOCOCCAL ANTIBODY DEVELOPMENT IN RHEUMATIC FEVER ${ }^{1}$
}

\author{
By ALVIN F. COBURN AND RUTH H. PAULI \\ (From the Department of Medicine, College of Physicians and Surgeons, Columbia University, \\ and the Presbyterian Hospital, New York City)
}

(Received for publication September 16, 1938)

It has been shown that patients with rheumatic fever continue to produce antibodies to hemolytic streptococcus for months after the subsidence of an apparently transient respiratory infection. The various clinical types of rheumatic fever are accompanied by characteristic types of antibody response. In monocyclic attacks with acute onset, a period of severe illness, and relatively rapid recovery, the titer reaches maximum relatively early-within a month of the onset of rheumatic symptoms. In attacks with insidious onset, where repeated cycles of progressive severity culminate in severe carditis months later, the titer rises more gradually, reaching its maximum height late in the illness (1). This close relation between the course of antibody production and the clinical character of the rheumatic attack has stimulated us to investigate the underlying reason for the prolonged development of streptococcal antibody in this disease.

The simple hypothesis that the infectious agent persists throughout the period of rising titer, does not lend itself to direct proof or disproof in the human subject. During convalescence from pharyngitis, hemolytic streptococcus commonly disappears from the mucosa of the upper respiratory tract, and only the occasional patient furnishes the opportunity to recover it later from deeper tissues, such as an accessory sinus, middle ear, or tonsils. The impossibility of thorough bacteriological studies of deep tissues in human subjects has obliged us to use an indirect approach to explain the significance of prolonged antibody development. The purpose of this paper is to summarize such indirect evidence as we have been able to obtain, and to indicate its bearing on the rheumatic fever problem. The data have been collected from naturally occurring throat infections in human subjects and from experimental infections in the guinea pig.

1 The work reported in this communication was carried out under the W. K. Kellogg Foundation Fund.
I. THE PROLONGED DEVELOPMENT OF BOTH ANTISTREPTOLYSIN AND ANTI-M SUBSTANCE

Quantitative studies have shown that the titer of antistreptolysin rises following uncomplicated streptococcal throat infections, reaching a maximum value in about three weeks following infection. $^{2}$ During continued rheumatic activity, however, this titer increases progressively for extended periods of time, sometimes as much as six months. The titer does not fall until recovery has begun. This is illustrated (Figure 1 ) by Patient E. G. who developed different types of rheumatic attacks in successive years (1934 intense monocyclic, 1935 insidious polycyclic).

Patient, E. G., Number 345168, a six-year old girl with rheumatic heart disease, was convalescing at the Pelham Home when in April 1934 she contracted pharyngitis with hemolytic streptococcus Group A, Type 26. Two weeks later she developed a severe attack of rheumatic fever, reaching maximum intensity one month after infection. At this time she had pancarditis and pulmonary consolidation. At the height of illness the antistreptolysin titer reached its peak, about five weeks after infection.

One year later this patient again contracted pharyngitis with hemolytic streptococcus Group A (not typed). Two weeks after infection she complained of fatigue and vague abdominal pain (Cycle 1 of rheumatism). Five weeks after infection she developed chest pain, slight erythema marginatum, and tachycardia (Cycle 2), although these symptoms were mild and the blood sedimentation rate rose to $100 \mathrm{~mm}$. per hour (Westergren). Five weeks after infection she developed severe precordial pain, polyarthritis and facial edema. This was the third cycle in the rheumatic attack but the first with frank clinical symptoms. There were four other classical cycles in the next four months. In contrast to the previous year the antistreptolysin titer rose slowly during this attack and did not reach its peak until about five to six months after infection.

This patient illustrates a characteristic relationship be-

2 Observations in the past have shown that other infections, including pneumonia, chickenpox, measles, mumps, common colds, influenza, appendicitis, and nonspecific agents (such as typhoid vaccine and tetanus antitoxin) do not increase the antistreptolysin titer. 

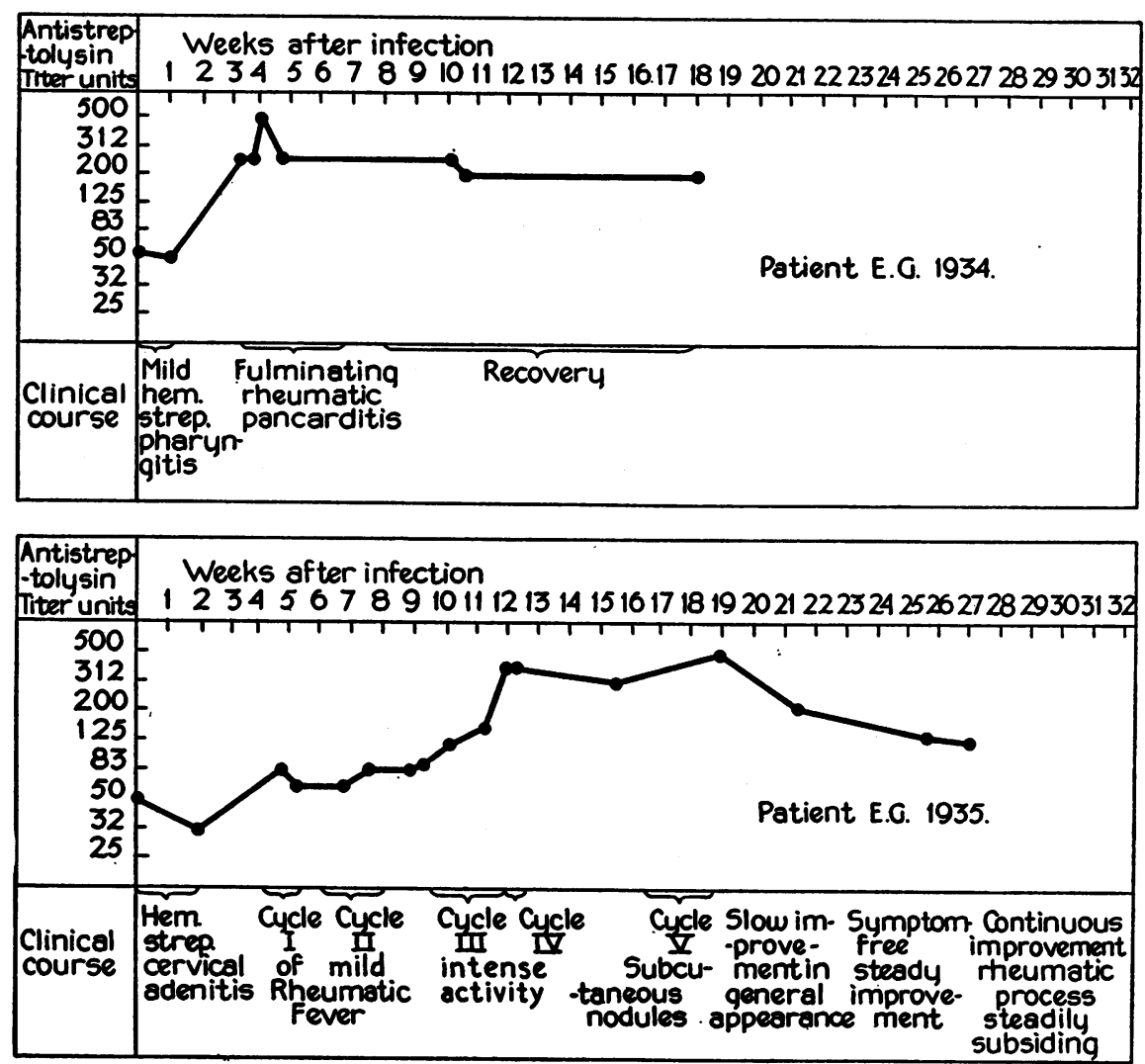

Fig. 1. The Antistreptolysin Curves Associated with Different Types of Rheumatic Attacks

tween titer curve and clinical course: severe, acute attack accompanied by early peak in antistreptolysin titer; prolonged polycyclic attack accompanied by a slowly rising titer reaching its peak several months after infection.

The presumable stimulus for this progressive increase in antistreptolysin is the continuous release of streptolysin into the tissues of the patient. If the release of streptolysin should occur alone, without other streptococcal antigens, streptolysin then would appear to be closely associated with the pathogenesis of rheumatic fever. However, if the prolonged development of antistreptolysin is accompanied by a similar development of other streptococcal antibodies, then the antistreptolysin response merely indicates that the infectious agent as a whole remains active somewhere in inaccessible tissues. To obtain evidence bearing on these possibilities, parallel studies were made of the development of antistreptolysin and of precipitins to Lancefield's type-specific $M$ substance.
Anti-M precipitins are known to occur in nonrheumatic subjects following hemolytic streptococcal throat infections $(2,3)$. They generally appear and subside a little later than antistreptolysin, being maximal at about 5 weeks after the onset of infection (3). Anti-M precipitins also occur in the sera of rheumatic patients, but we have not followed the course of their development in relation to antistreptolysin except in a few isolated cases (3). We therefore conducted the following study.

\section{Procedure}

Sera were collected from rheumatic subjects at weekly intervals from the onset of pharyngitis over a period of three to six months. Sixteen individuals who developed rheumatic fever comprise the group reported in this study. Each sample of serum was tested in three ways. Antistreptolysin was titrated according to our standard procedure (4). Anti-M type-specific precipitins were estimated according to Lancefield's method (5). Typespecific agglutinins were estimated according to the slide agglutination technique originally described by Griffith 
(6) and used by ourselves (7), for the typing of hemolytic streptococcus. Type-specific M-substances for the precipitin tests were prepared by extracting cultures of the organism recovered from the patient's throat during the acute infection. The slide agglutination tests were carried out on the patient's serum with suspensions of the patient's organism and with control suspensions of other serological types.

\section{Results}

All sixteen patients developed a striking rise in the antistreptolysin titer, and all developed type-specific antibodies. Fourteen showed precipitins and eleven gave slide agglutination reactions. The times when maximum titers occurred are shown in Table I.

TABLE I

Time of occurrence in the rheumatic attack of the patient's maximum antibody level

\begin{tabular}{|c|c|c|c|c|}
\hline \multirow{3}{*}{ Patient } & \multicolumn{3}{|c|}{ Week of rheumatic attack } & \multirow{3}{*}{ Clinical condition } \\
\hline & \multirow{2}{*}{$\begin{array}{c}\text { Antistrep- } \\
\text { tolysin }\end{array}$} & \multicolumn{2}{|c|}{ Anti-M } & \\
\hline & & Precipitin & Agglutinin & \\
\hline 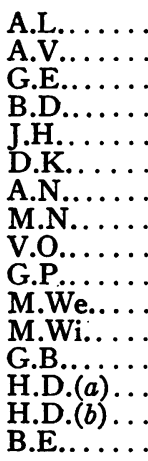 & $\begin{array}{r}3 \\
10 \\
3 \\
3 \\
3 \\
3 \\
10 \\
5 \\
4 \\
3 \\
1 \\
5 \\
1 \\
1 \\
6 \\
6\end{array}$ & $\begin{array}{r}2 \\
18 \\
7 \\
12 \\
6 \\
5 \\
12 \\
3 \\
9 \\
2 \\
2 \\
8 \\
3 \\
2 \\
8\end{array}$ & $\begin{array}{l}9 \\
1 \\
8 \\
2 \\
6 \\
8\end{array}$ & $\begin{array}{l}\text { Height of attack } \\
\text { Early subsidence } \\
\text { Height of attack } \\
\text { Early subsidence } \\
\text { Height of attack } \\
\text { Early subsidence } \\
\text { Subsiding } \\
\text { Subsiding } \\
\text { Early subsidence } \\
\text { Early subsidence } \\
\text { Height of attack } \\
\text { Convalescing } \\
\text { Height of attack } \\
\text { Height of attack } \\
\text { Height of attack } \\
\text { Subsiding }\end{array}$ \\
\hline
\end{tabular}

In the majority of cases antibody to the Msubstances continued to increase after the antistreptolysin titer had reached its maximum level. Hence any prolongation of the immune response in these patients affected both antibodies, and not antistreptolysin alone. These findings point to the prolonged activity of hemolytic streptococcus as a whole.

II. THE EFFECT OF POSTSTREPTOCOCCAL SEPTIC COMPLICATIONS ON ANTIBODY PRODUCTION

Preliminary observations on non-rheumatic subjects (3) indicated that in the absence of com- plications, maximum antistreptolysin titers were usually reached within three weeks after the onset of scarlet fever and pharyngitis. Subsequent studies have been made of a larger group of patients during recovery from streptococcal respiratory infections. Some of these had normal recoveries and others developed septic complications.

Eighty-five cases, including fifty-four of scarlet fever and thirty-one of pharyngitis, were studied from the onset of infection through convalescence, for periods varying from six to sixteen weeks. Of fifty-nine patients who had normal recoveries, fifty-seven reached their maximum titer within a month, and two were delayed beyond a month. Twenty-six patients had complications of varying degrees of severity. Of these, only fourteen reached maximum titer within a month. The data for patients with and without complications are presented in Table II.

TABLE II

The number of patients reaching their maximum antistreptolysin titer at various times after the onset of streptococcal throat infections

\begin{tabular}{c|r|r|r|r|r|r}
\hline \hline & \multicolumn{3}{|c}{$\begin{array}{c}\text { Weeks after onset of } \\
\text { infection }\end{array}$} \\
\cline { 2 - 5 } Patients with & 1 & 2 & 3 & 4 & Later \\
\hline Uncomplicated recoveries (59) .... & 12 & 19 & 17 & 9 & 2 \\
Septic complications (26) ......... & 2 & 5 & 4 & 3 & 12 \\
\hline
\end{tabular}

The development of a septic complication was followed in most cases by a further rise in antistreptolysin titer; and the time of this rise deperided on when the complication appeared. Late increases in antibody titer occurred in fourteen patients. Twelve of these late rises were associated with demonstrable active infection.

In summary, it appeared that the antistreptolysin titer increased as long as the infectious agent continued to be active.

\section{THE EXPERIMENTAL PRODUCTION OF A PRO- LONGED ANTISTREPTOLYSIN RESPONSE}

It has been possible to produce an increase in antistreptolysin titer in guinea pigs by infecting them experimentally with Group A hemolytic streptococcus, N.Y.5. Using the agar focus technique, $\mathrm{McBroom}$ in this laboratory induced 
the development of antistreptolysin titers ranging from 50 to 1000 units in 33 out of 37 animals. (Uninfected controls had titers of 0 to 10 units.) The agar foci gave rise to abscesses which ruptured spontaneously and healed, as a rule, within 6 weeks. With healing, the titers either remained at plateau level without further rise for a number of weeks, or fell rapidly to zero.

Attempts were made to raise the titers of these guinea pigs still further by the injection of various nonspecific antigens. Filtrates from $B$. $t y$ phosus, $B$. Leptisepticus, and meningococcus were administered either intravenously, intrapericardially, subcutaneously, or intracutaneously. None of these materials had any effect on the antistreptolysin titer levels.

It was possible, however, to induce secondary rises in titer more than two months after the original focus, by the introduction of a new agar focus after the healing of the primary lesion. Fifteen guinea pigs were treated in this way, eight receiving the new focus before and seven receiving it after the titer induced by the first infection had subsided. Thirteen of these animals developed higher antistreptolysin titers after the healing of the second focus than they had shown after the first. Of the seven pigs whose second focus was given after the antibody titer to the first had subsided, six showed a greater response to the second focus than they had to the first. Five pigs received a third focus, which in each case gave rise to a new increase in titer. The effect of repeated foci on the antistreptolysin titers of guinea pigs is shown in Figure 2.

In summary, the progressive development of high antistreptolysin levels in the guinea pig appeared dependent upon repeated infections with hemolytic streptococcus.

\section{THE RELATION OF INFECTION TO THE ANTI-} STREPTOLYSIN TITER CURVE IN GUINEA PIGS

Another group of 25 pigs was given agar foci and sacrificed at intervals thereafter. Bleedings were taken from the heart every three weeks for antistreptolysin determinations. Six pigs with suppurative lesions and six others with healed foci were killed during the period of rising titers (before 6 weeks). The remaining thirteen pigs were autopsied at the end of 2 months or later,

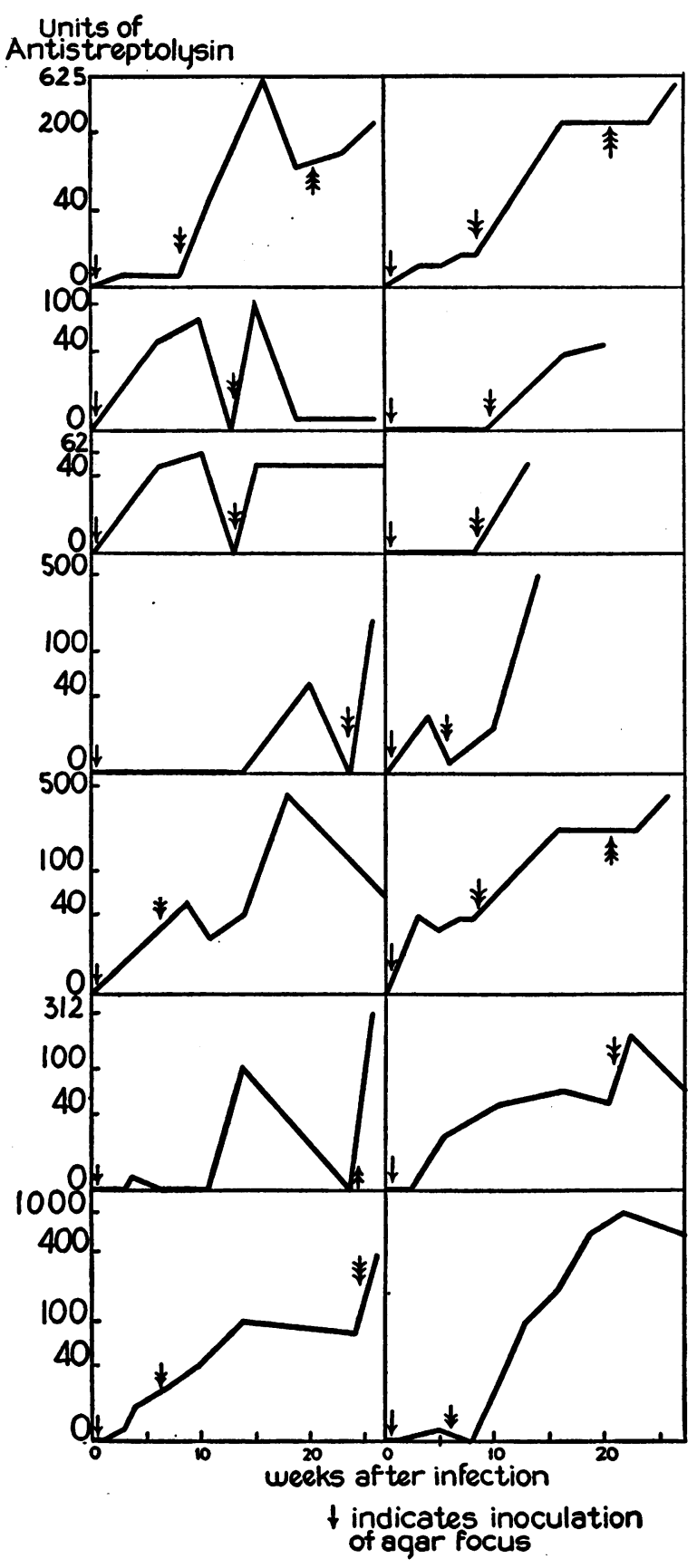

Fig. 2. Antustreptolysin Curves in Guinea Pigs folLOWing the Induction of Streptococcal Abscesses

when their foci had healed and their titers had reached a maximum. Careful bacteriological studies were made from the site of the focus, heart's blood, lymph nodes, spleen, liver, and kidney. 
The results of these cultures were as follows. No organisms were recovered from guinea pigs with stationary or falling titers, irrespective of when the animals were killed. The twelve pigs killed during the period of rising titer had viable organisms in the depths of the foci.

\section{SUMMARY}

Findings are presented which support the view that prolonged increases in streptococcal antibody, such as are observed in rheumatic fever, signify subclinical activity of hemolytic streptococcus.

The authors are indebted to Drs. Josephine McBroom and Samuel Hunt for their help in the animal experiments.

\section{BIBLIOGRAPHY}

1. Coburn, A. F., and Pauli, R. H., Studies on the immune response of the rheumatic subject and its relationship to activity of the rheumatic process. J. Clin. Invest., 1935, 14, 769.

Specific and non-specific changes in blood protein during acute rheumatism with carditis. Internat. Clin., 1936, 4, 49.

2. Swift, H. F., and Hodge, B. E., Type-specific-anti-M precipitins in rheumatic and non-rheumatic patients with hemolytic streptococcal infections. Proc. Soc. Exper. Biol. and Med., 1936, 34, 849.

3. Coburn, A. F., Observations on the mechanism of rheumatic fever. Lancet, 1936, 2, 1025.

4. Coburn, A. F., and Pauli, R. H., Studies on the immune response of the rheumatic subject and its relationship to activity of the rheumatic process. J. Exper. Med., 1935, 62, 129.

5. Lancefield, R. C., The antigenic complex of Streptococcus haemolyticus. J. Exper. Med., 1928, 47, 91.

6. Griffith, F., The serological classification of Streptococcus pyogenes. J. Hyg., 1935, 34, 542.

7. Pauli, R. H., and Coburn, A. F., Studies on the serological typing of Streptococcus haemolyticus. J. Exper. Med., 1937, 65, 595. 